\title{
PROCESSO DE PRODUÇÃO DE ETANOL A PARTIR DA HIDRÓLISE ÁCIDA DE BIOMASSAS LIGNOCELULÓSICAS
}

\author{
R.. C. BONISSATTO ${ }^{1}$, D.J. SILVA ${ }^{1}$ J. M. de ALMEIDA ${ }^{2}$, F. A. RODRIGUES ${ }^{1}$, S. T. RESENDE ${ }^{3}$ e \\ A. B. de MENDONÇA NETO ${ }^{1}$ \\ ${ }^{1}$ Universidade Federal de Viçosa, Departamento de Química \\ ${ }^{2}$ Universidade Federal do Recôncavo da Bahia, Centro de Ciências Agrárias, Ambientais e \\ Biológicas \\ ${ }^{3}$ Universidade Federal de Viçosa, Departamento de Bioquímica e Biologia Molecular \\ E-mail para contato: deusanilde@ufv.br
}

\begin{abstract}
RESUMO - O objetivo deste trabalho foi a avaliação do potencial de três biomassas (bagaço de cana, papéis recicláveis e algodão) para produção de bioetanol, via hidrólise ácida. Inicialmente, as matérias-primas foram caracterizadas por microscopia eletrônica de varredura (MEV), difratometria de raios - X e análises de viscosidade. A avaliação da etapa de desconstrução e o estudo cinético da sacarificação foram realizados através da quantificação de açúcares por massa de partida. Foram avaliados os rendimentos de produção de etanol por meio de picnometria. Através dos índices de cristalinidade obtidos pelas análises de difratometria de raios - X, foi possível concluir que a biomassa fibras de algodão apresentou rede cristalina mais organizada e a biomassa bagaço de cana menos organizada. A biomassa aparas de papel situou-se em posição intermediária. As fotomicrografias conduziram a observações que estão de acordo com os resultados de difratometria de raios- $\mathrm{X}$ e de viscosidades das biomassas. Por meio da curva cinética foi possível verificar que as biomassas bagaço de cana e fibras de algodão respondem, respectivamente, de forma mais e menos eficiente à hidrólise ácida quanto à produção de açúcares fermentescíveis. Isso pode ser atribuído à rede cristalina das biomassas. Entretanto, maior rendimento em etanol foi alcançado pela biomassa fibra de algodão.
\end{abstract}

\section{INTRODUÇÃO}

Com o aumento do consumo de etanol nos últimos anos, obtido principalmente da fermentação de açúcares provenientes de fontes sacarinas e amiláceas, o interesse em obter novas fontes de matérias-primas para produção desse combustível é crescente. O novo conceito de bioetanol corresponde à produção de etanol a partir de fontes como biomassas lignocelulósicas, o conhecido etanol de segunda geração. Essas matérias-primas são abundantes, pois podem ser provenientes de resíduos industriais e da agricultura como: bagaço de cana-de-açúcar, aparas de papéis, sabugo de milho, dentre outras. Durante a safra 2012/2013, mais de 588,9 milhões de toneladas de cana-de-açúcar foram moídas e geraram cerca de 159 milhões de toneladas de bagaço (CONAB, 2013). A maior parte foi queimada em caldeiras para cogeração de energia, no entanto, cerca de $20 \%$ desse montante foi rejeitado pelo setor sucroalcooleiro (Leal e Castro, 2012). Considerando o setor papeleiro, a produção total de papel no Brasil em 2013 foi de 10,4 


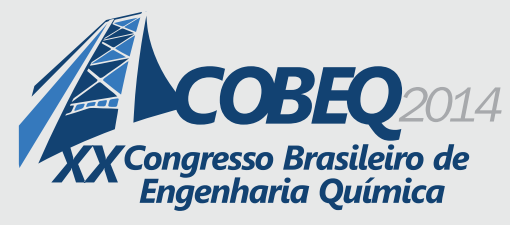

19 a 22 de outubro de 2014

Florianópolis/SC

milhões de toneladas e o consumo de papel reciclado (aparas) em 2012 alcançou 4,4 milhões de toneladas (BRACELPA, 2014). As fibras de algodão são consideradas muito puras apresentando elevado teor de celulose (Edwards, Farwell e Webster, 1997). Os resíduos de algodão gerados na a $8 \%$ do total do algodão processado. No ano de 2010, a indústria de fiação consumiu, aproximadamente, 1.494 mil toneladas de matéria-prima (naturais, artificiais e sintéticas) para a fabricação de fios. A participação do consumo da fibra de algodão no contexto geral da produção de fios foi da ordem de $80 \%$ (Aquino, D.F., 2013). Os polissacarídeos representam parte considerável do peso seco da parede e consistem em celulose (polissacarídeo linear formado por moléculas de glicose ligadas através de ligações $\beta-1,4$ - glicosídicas), que compõe de 20 a $40 \%$ da parede, hemiceluloses (15 a 25\%) e lignina (20-25\%) e outros componentes que não fazem parte da parede celular como os extrativos (Ogeda e Petri, 2010). Os teores de celulose das biomassas algodão, papéis recicláveis e bagaço de cana apresentados na literatura são $90 \%$ (Edwards et al., 1997), 80\% (Silva, 2010) e 42,8\% (Gouveia et al., 2009), respectivamente. Um dos desafios para a obtenção de etanol de biomassa lignocelulósica está relacionado ás etapas de desconstrução e de sacarificação da mesma. As cadeias de celulose estão unidas entre si por ligações de hidrogênio formando as microfibrilas e, por sua vez, essas são recobertas por hemiceluloses e lignina formando uma matriz complexa que constitui a parede celular (D’Almeida et al., 2013). A matéria-prima mais utilizada para a produção de etanol é a sacarose da cana-de-açúcar, mas a partir da viabilização da produção desse combustível empregando materiais lignocelulósicos, é possível aumentar sua produção por hectare plantado (Finguerut et al., 2008; Bastos, 2007). Para tanto, seria necessário a desconstrução/sacarificação da parede celular para utilização dos polissacarídeos como açúcares fermentescíveis. Essa etapa de obtenção de monossacarídeos passíveis de serem fermentados pode ser realizada por via química ou via enzimática (Rossell e Zainaghi, 2008). No primeiro, o objetivo é a utilização de ácidos minerais para realizar o ataque aos polissacarídeos. Essa etapa é dificultada pela rede cristalina formada pela celulose, com baixa reatividade e acessibilidade, o que dificulta a ação de agentes químicos (Wenzl, 1970; Ogeda e Petri, 2010). O processo de hidrólise ácida consiste na utilização de um ácido forte para clivar as ligações glicosídicas entre os monossacarídeos, normalmente opta-se pelos ácidos sulfúrico e clorídrico. O ácido trifluoroacético quebra preferencialmente ligações mais fracas, que são do tipo alfa $(\alpha)$, presentes nas ramificações das hemiceluloses, enquanto os ácidos sulfúrico e clorídrico discriminam pouco as ligações glicosídicas, agindo de forma similar sobre a celulose e as hemiceluloses (Wenzl, 1970). A celulose é o último polissacarídeo a ser hidrolisado devido à sua complexa interação intermolecular, à completa ausência de água na estrutura das microfibrilas e pelas hemiceluloses envolver as microfibrilas. O tempo de hidrólise ácida das ligações do tipo alfa ( $\alpha)$ e beta $(\beta)$ é diferente, por consequência, no processo que envolva a utilização de biomassas com polímeros que contenham diferentes tipos de ligações, como o caso de celulose e hemiceluloses, é necessário bom controle dessa variável. Os monossacarídeos liberados antes tendem a degradarse, sofrendo caramelização, e quando essa for intensa, formam-se furfurais ou hidroximetilfurfural, os quais são tóxicos para as leveduras na etapa de fermentação do hidrolisado. Portanto, na hidrólise de uma mistura de celulose e hemiceluloses, a desconexão temporal das quebras das ligações glicosídicas torna-se um entrave (Wenzl, 1970; Taherzadeh e Karimi, 2007). Dessa forma, o objetivo desse trabalho é a avaliação do potencial para produção de bioetanol de três biomassas distintas. 


\section{9 a 22 de outubro de 2014 \\ Florianópolis/SC}

\section{MATERIAIS E MÉTODOS}

\subsection{Materiais}

As biomassas foram: (a) papéis usados provenientes de rejeito de impressão produzidos a partir de polpa kraft branqueada de eucalipto, conhecidas no meio como aparas de papéis; (b) fibras de algodão comerciais obtidas no comércio local, e (c) bagaço de cana, compreendendo ao rejeito de lanchonete local, que será chamado apenas de bagaço.

\subsection{Métodos}

Pré-tratamento das matérias-primas: as amostras de biomassa, antes e após cada etapa, tiveram seu teor a.s. (absolutamente seco) determinado de acordo com a norma TAPPI T421 om02. Todas as amostras foram acondicionadas em em sacos de polietileno. A amostra de papéis usados não sofreu nenhum tratamento químico. Após a sua amostragem, foram cortados em pedaços menores $(\sim 1,5 \times 1,5 \mathrm{~mm})$. A biomassa algodão comercial foi submetida à extração com acetona P.A. em aparelhagem Soxhlet para remover os componentes hidrofóbicos da superfície das fibras. Foram adotados 6 ciclos/h durante 4 horas. Após a extração, as fibras foram secas à temperatura ambiente. $\mathrm{O}$ bagaço foi, inicialmente, transformado em serragem e submetido à extração com solventes para remoção de extrativos (TAPPI T 204 om-88). Posteriormente, a amostra foi deslignificada em duas etapas: (1) Miranda et al. (2012) e (2) Perez et al, (2011). Por fim, a amostra foi submetida à remoção de hemiceluloses de acordo com a metodologia proposta por Silva et al., (2011).

Análises das biomassas por difratometria de raios-X: Amostras de biomassa foram submetidas à difratometria de raios-X (PANalytical modelo X'Pert PRO) no Laboratório de Mineralogia (Departamento de Solos - UFV) para obter informações a respeito do grau de cristalinidade das matérias-primas usadas na produção de bioetanol. Conforme Segal et al. (1959), o índice de cristalinidade foi calculado pela Equação 1, o índice de cristalinidade (IC) é dado pela diferença entre uma unidade e a razão entre a intensidade do mínimo $\left(\mathrm{I}_{\min }\right)$ e do máximo $\left(\mathrm{I}_{\max }\right)$ de difração relacionado à parte amorfa e cristalina, respectivamente.

$$
\mathrm{IC}=1-\mathrm{I}_{\min } / \mathrm{I}_{\max } \quad \text { (Equação 1) }
$$

Determinação do grau de degradação das biomassas: o grau de degradação das amostras foi avaliado de acordo com a medida de viscosidade de suas cadeias celulósicas após individualização com solução alcalina de etileno diamina cúprica, a qual foi adaptada da norma TAPPI T230 om-82.

Avaliação da estrutura das biomassas por microscopia: Fragmentos de cada biomassa foram montados sobre suportes metálicos de alumínio. Em seguida, foram desidratados em dessecador com sílica gel por $72 \mathrm{~h}$. Após, os fragmentos foram revestidos com ouro em pó por meio de metalização no aparelho Sputter Coater acoplado a um Freezing Drying Unit (Balzers, FDU010). Os fragmentos foram examinados através de microscópio eletrônico de varredura (LEO, modelo 1430VP) operado a $20 \mathrm{Kv}$ para a obtenção das fotomicrografias com aumento de 250x.

Avaliação das etapas de desconstrução e de sacarificação das biomassas: Para efeito de comparação do comportamento das três biomassas, após a etapa de desconstrução com ácido sulfúrico $72 \% \mathrm{p} / \mathrm{p}$, a quantidade de glicose foi quantificada. Com o objetivo de obter a cinética de sacarificação das biomassas, a etapa de sacarificação com ácido sulfúrico a $36 \%$ p/p foi 


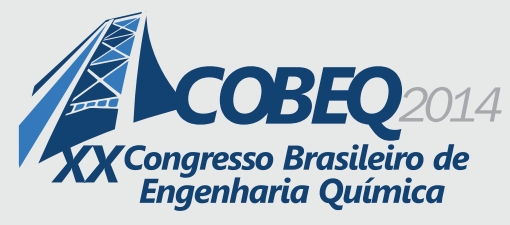

19 a 22 de outubro de 2014
Florianópolis/SC

acompanhada mediante a quantificação de glicose em função do tempo de sacarificação. Para ambas as etapas, foi utilizado o método enzimático glicose monorreagente K082 da Bioclin, o qual é específico para a detecção de glicose e posterior leitura em espectrofotômetro (marca Spectrum, modelo SP-1105). Seguiu-se metodologia do fabricante. Curva padrão com concentrações conhecidas de glicose anidra. Os padrões para as leituras foram preparados na proporção de 4:1:5, em volume, de água destilada, solução de glicose e reagente, respectivamente. Esses foram, então, colocados em banho-maria à $35^{\circ} \mathrm{C}$ por 15 min para garantir atividade ótima das enzimas. As absorbâncias dos padrões foram lidas em $510 \mathrm{~nm}$. As alíquotas para cada amostra foram utilizadas na preparação para leitura, com metodologia igual à conduzida para elaboração da curva padrão. Os valores de absorbância foram relacionados às concentrações por meio da curva analítica de referência.

Hidrólise ácida e obtenção do etanol: Desconstrução da macroestrutura das biomassas $e$ sacarificação dos polissacarídeos: $\mathrm{Na}$ desconstrução, foi utilizado ácido sulfúrico $72 \% \mathrm{p} / \mathrm{p}$, na proporção de $15 \mathrm{~mL}$ do ácido para $1 \mathrm{~g}$ de biomassa seca, à temperatura ambiente e sob agitação constante com bastão de vidro por, aproximadamente, 20 minutos. Ao final desta etapa, obteve-se uma mistura líquida, uniforme, de coloração caramelo escuro. A mistura, então, foi alimentada em um reator de vidro bateladas com três bocas, contendo $120 \mathrm{~mL}$ de água destilada pré-aquecida, em que a concentração de ácido sulfúrico foi reduzida para, aproximadamente, de $36 \%$ p/p quando deu-se início a sacarificação. A mistura foi mantida a, aproximadamente, $90^{\circ} \mathrm{C}$ por 90 minutos sob agitação constante. A reação foi paralisada imergindo a mistura em banho de gelo. Neutralização e ajuste de pH: A neutralização foi feita com hidróxido de cálcio até $\mathrm{pH}$ próximo a 4,5 com o objetivo de remover o íons sulfato presentes na solução e de fornecer as condições favoráveis à atividade das leveduras. O sulfato de cálcio formado foi removido por filtração e armazenado para posterior destinação. Caso necessário, o ajuste fino era realizado com soluções $0,1 \mathrm{~mol} \mathrm{~L}^{-1}$ de $\mathrm{HCl}$ e de $0,1 \mathrm{~mol}$ $\mathrm{L}^{-1}$ de $\mathrm{NaOH}$. Ajuste do teor de açúcares e fermentação: $\mathrm{O}$ teor de açúcares aparente do filtrado foi medido com um refratômetro portátil. Caso necessário, a água era evaporada para ajuste do ${ }^{\circ}$ Brix entre 12 e $14^{\circ}$ Brix. O produto da sacarificação foi adicionado em um reator de fermentação de 250 $\mathrm{mL}$ em batelada com controle de temperatura e agitação em ambiente de anaerobiose juntamente com cerca de $7 \mathrm{~g}$ de fermento biológico hidratado composto por $\sim 10 \%$ de levedura Saccharomyces cerevisiae. O tempo de fermentação foi em torno de 16 horas e a temperatura foi mantida entre 25 e $30{ }^{\circ} \mathrm{C}$. Após o término da fermentação, a mistura foi submetida à filtração de forma que a suspensão de leveduras fosse removida. Destilação e determinação do teor alcoólico: A destilação foi realizada em um minissistema de destilação simples projetado e confeccionado na UFV. O volume obtido de etanol recolhido era de, aproximadamente, $25 \mathrm{~mL}$. Para mensurar o teor alcoólico da solução hidroalcoólica foi utilizado o método indireto da medição da densidade por picnometria, utilizando de $10 \mathrm{~mL}$ da solução à $20^{\circ} \mathrm{C}$. A partir da densidade da solução hidroalcoólica, foi possível determinar o teor de etanol através de tabela de conversão em graus Gay Lussac e, posteriormente, o volume e a massa de etanol celulósico produzido. O rendimento com base no material de partida foi calculado dividindo a massa de etanol produzida pela massa absolutamente seca da biomassa submetida à hidrólise. Todas as etapas foram realizadas com, no mínimo, três repetições.

\section{RESULTADOS E DISCUSSÃO}

\subsection{Difratometria de raios-X e viscosidade das amostras de biomassas}


Informações sobre a estrutura cristalina das biomassas em relação à estrutura amorfa estão apresentadas na Figura 1. Segundo o método de Segal et al. (1959), o índice de cristalinidade corresponde à diferença entre uma unidade e a razão entre a intensidade do mínimo e do máximo de difração. Sendo assim, o algodão, o papel e o bagaço apresentaram índices de cristalinidade de $82,8 \%$, $77,3 \%$ e $77,1 \%$, respectivamente (Figura 1). Portanto, enquanto o algodão apresentou estrutura menos disponível para o ataque pelo ácido na hidrólise, o que dificultaria a formação de açúcares fermentescíveis, o bagaço e o papel apresentaram estruturas mais acessíveis ao ataque dos íons $\mathrm{H}^{+}$. Embora seja visível pelo gráfico que o bagaço apresentou grau de cristalinidade inferior, devido ao pico referente à intensidade de máximo não ser tão proeminente quanto aos demais. A viscosidades das biomassas estão de acordo com os resultados da difratometria de raios-X, já que maior valor de viscosidade está relacionado com maior grau de polimerização, conforme é mostrado no trabalho de Krässing (1993), e, consequentemente, a uma estrutura com maior grau de organização e, portanto, cristalinidade. Dessa forma, o bagaço, que apresenta uma viscosidade de $15,0 \pm 0,10 \mathrm{cP}$, seria mais acessível ao ataque ácido na hidrólise do que o papel $(26,3 \pm 0,07 \mathrm{cP})$ e o algodão $(58,0 \pm 0,07 \mathrm{cP})$, sendo este o que apresentou as cadeias de celulose com maior grau de polimerização do que as duas outras biomassas.

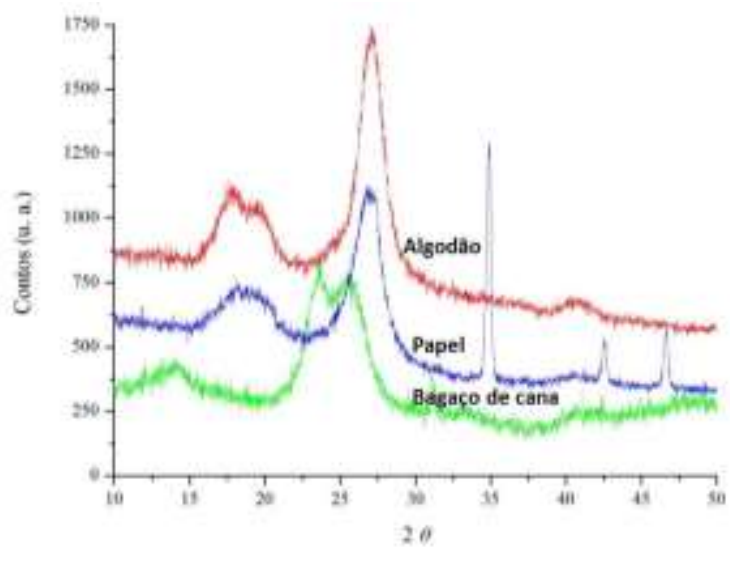

Figura 1: Curvas comparativas de difratometria de raios-X para as diferentes biomassas.

\subsection{Microscopia eletrônica de varredura (MEV)}

De acordo com as imagens obtidas por MEV (Figura 2), é possível identificar maior integridade das fibras de algodão (Figura 2-III) em relação ao bagaço (Figura 2-I) e ao papel (Figura 2-II). No bagaço, são visíveis fibras mais curtas e a presença de finos, o que poderia facilitar o ataque ácido à biomassa. As fibras dos papéis recicláveis (Figura 2-II) apresentaram características intermediárias comparadas às carateríticas morfológicas do bagaço e do algodão. Dessa forma, as imagens estão de acordo com os resultados de difratometria de raios-X (Figura 1) e de viscosidades das biomassas. 


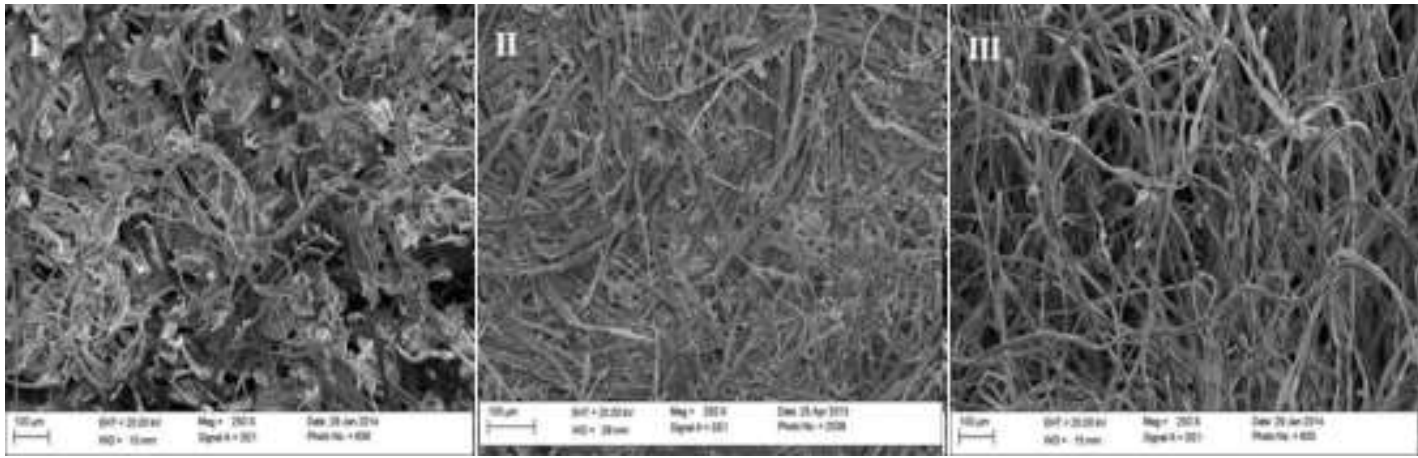

Figura 2: Fotomicrografias das biomassas: bagaço (I), papel (II) e algodão (III) antes da hidrólise.

\subsection{Avaliação da desconstrução e da sacarificação das biomassas e rendimentos em bioetanol}

A produção de açúcares fermentescíveis apresentada na Figura 3 é dada pela razão entre a glicose produzida pela biomassa seca de partida $(\mathrm{m} / \mathrm{m})$. Considerando a etapa de sacarificação, $o$ bagaço é mais facilmente hidrolisado quando comparado às demais biomassas (Figura $3, \mathrm{~B}$ ). Esse fato pode ser explicado mediante a análise de sua estrutura cristalina por meio de difratometria de raios-X (Figura 1) e do grau de polimerização dado pela viscosidade $(15,0 \pm 0,10 \mathrm{cP})$ dessa biomassa quando comparada aos resultados de viscosidade do papel $(26,3 \pm 0,07 \mathrm{cP})$ e do algodão $(58,0 \pm 0,07 \mathrm{cP})$. O comportamento cinético apresentado pelas três biomassas nos primeiros 60 min foi foram foram diferentes (Figura 3-B). Também, o tempo para atingir o equilíbrio para as três biomassas mostrou-se diferentes. Comparando a curva para o bagaço e para o algodão, esta última parece ser necessário mais tempo para atingir o equilíbrio do que o bagaço, considerando as mesmas condições da hidrólise. Maior tempo de hidrólise, poderia gerar maior quantidade de glicose por biomassa de partida. De acordo com os resultados de rendimento mostrados na Figura 3-C, dado em gramas de etanol produzido por grama a. s. de biomassa de partida, os resultados obtidos foram o inverso do esperado. Ou seja, o bagaço com maior teor específico de glicose após a etapa de hidrólise $(0,22 \mathrm{~g} / \mathrm{g})$ apresentou menor resultado de rendimento (12\%), (comparar Figura 3-B com Figura 3-C). O algodão, com menor teor de glicose específica (0,02 $\mathrm{g} / \mathrm{g}$ ) apresentou maior rendimento em etanol (23\%), (comparar Figura 3-B com Figura 3-C). Os resultados alcançados para a biomassa papel foram intermediários. Uma hipótese para explicar este comportamento poderia ser formulada com base na pureza do material de partida com relação aos inibidores como extrativos e lignina, embora tenha sido feito pré-tratamentos para remoção dessas subtâncias. Segundo Soares (2013), a eficiência de conversão de celulose em glicose e os rendimentos na etapa de fermentação dependem do teor e distribuição de lignina no material, o que justifica maiores rendimentos para materiais com teores de lignina inferiores. Dessa forma, para verificação dessa hipótese, análise química do material é sugerida. Considerando os resultados da literatura para rendimento em etanol, Mascal e Scown (2008) obtiveram aproximadamente $0,125 \mathrm{~g}$ de etanol a partir de $1 \mathrm{~g}$ de papel jornal, biomassa que além de celulose e hemiceluloses, possui lignina devido ao processo mecânico de obtenção desse tipo de biomassa. Isto corresponde a um rendimento em etanol base papel jornal de 12,5\%, portanto, 
inferior ao rendimento obtido utilizando as biomassas algodão e papel e superior ao obtido para bagaço de cana. No entanto, as condições de fermentação empregadas por Mascal e Scown (2008) foram distintas da utilizada no presente trabalho (adicionou-se nutrientes para a levedura, não especificou a cepa de leveduras).
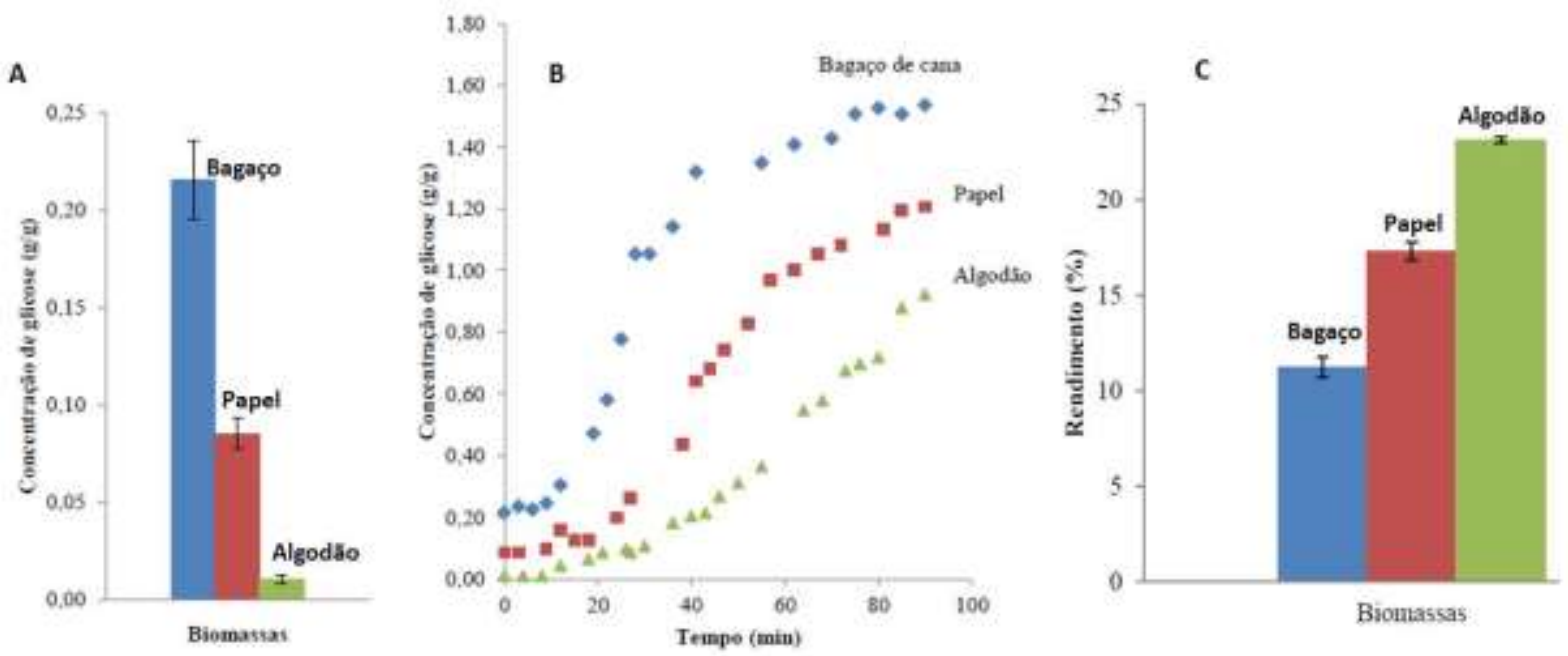

Figura 3: Quantificação da glicose após a etapa de desconstrução (A) e ao longo da sacarificação (B) e rendimento em bioetanol (C) para as três biomassas.

\section{CONCLUSÕES}

De acordo com os resultados alcançados, as conclusões abaixo podem ser enumeradas: (a) Através dos índices de cristalinidade obtidos pelas análises de difratometria de raios - X, foi possível concluir que a biomassa algodão tem rede cristalina mais organizada e a biomassa bagaço de cana menos organizada. A biomassa papel situou-se em posição intermediária. As fotomicrografias conduziram a observações que vão de acordo com os resultados de difratometria de raios-X e viscosidades das biomassas; (b) Por meio da curva cinética foi possível verificar que as biomassas bagaço e algodão respondem, respectivamente, de forma mais e menos eficiente à hidrólise ácida quanto à produção de açúcares fermentescíveis. Isso pode ser atribuído à rede cristalina das biomassas. Entretanto, maior rendimento em etanol foi alcançado pelo algodão; (c) embora os resultados tenham sido menos satisfatórios para o bagaço, esta biomassa possui grande potencial para produção de etanol em razão da sua quantidade disponível (31,8 milhões de t) em comparação com o papel (6 milhões de $t$ ) e com o algodão (0,12 milhões de $t$ na fiação). Mais estudos seriam necessários, especialmente a determinação da composição química das biomassas e o comportamento da etapa de fermentação.

\section{AGRADECIMENTOS}

Os autores agradecem aos profissionais do Núcleo de Microscopia e Microanálise da UVF, Karla Gonçalves e Gilmar Valente, pela colaboração na obtenção das imagens. Os autores também agradecem às agências de fomento FAPEMIG e CNPq pelo apoio financeiro. 


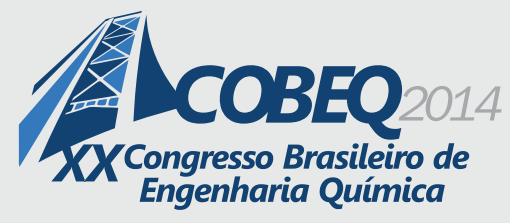

\section{REFERÊNCIAS}

AQUINO, D.F. ALGODÃO - PROSPECÇÃO PARA SAFRA 2012/13. Conab - 2013.

BASTOS, V. D. Etanol, alcoolquímica e biorrefinarias. Banco Nacional de Desenvolvimento Econômico e Social Setorial, Rio de Janeiro, n. 25, p. 5-38, março, 2007.

CONAB-Acompanhamento da safra brasileira cana-de-açúcar. Safra 2012/2013. Disponível em: <http://www.conab.gov.br/conteudos.php?a=1253\&t=>.Acesso em:10/12/13.

D'AlMEIDA, M. L. O., KOGA, M. E. T., FERREIRA, D.C., PIGOZZO, R. J. Composição química da madeira e matérias-primas fibrosas. In: SILVA, R. F. (ed.). Celulose. SENAI:São Paulo, p.11-58. p. 352, 2013.

EDWARDS, H.G.M., FARWELL, D.W., WEBSTER, D. FT Raman microscopy of untreated natural plant fibres. Spectrochimica Acta, v. 53, Part A, p. 2383-2392, 1997.

Estatísticas BRACELPA, Relatório Anual. Associação Brasileira de Celulose e Papel, 2014. Disponível em:<http://www.bracelpa.org.br/bra2/index.php>. Acesso em: 03/02/14.

FINGUERUT, J., MEIRELLES, A. J. A., GUIRARDELlO, R., COSTA, A. C. Fermentação, hidrólise e destilação. Cap. 13. In: CORTEZ, L. A. B., LORA, E. E. S., GÓMEZ, E. O. (Org.). Biomassa para Energia. Campinas: UNICAMP, p. 435-474.p.732, 2008.

GOUVEIA, E. R., NASCIMENTO, R. T., SOUTO-MAIOR, A. M., ROCHA, G. J. M. Validação de metodologia para a caracterização química de bagaço de cana-de-açúcar. Química Nova, v. 32, n. 6, p. 1500-1503, 2009.

KRÄSSING, H. A., ed. Cellulose: Structure, Accessibility and Reactivity. Gordon and Breach Science Publishers: Yverdon, Switzerland. 376 p. 1993.

LEAL, C. L. D. ; CASTRO, P. F. Construção de um trecho experimental em SMA usando bagaço de cana-de-açúcar como aditivo. Vértices, v. 14, p. 71-84, 2012.

MASCAL, M., SCOWN, R. Converting Municipal Waste into Automobile Fuel: Ethanol from Newspaper. Journal of Chemical Education, v. 85(4), p. 546-548, 2008.

MIRANDA, C. S., SOUZA, A. S., FERREIRA, L. C. S., JOSÉ, N. M. Whiskers de fibras de bananeiras obtidos sob diferentes condições de hidrólise ácida. $20^{\circ}$ Congresso Brasileiro de Engenharia e Ciência dos Materiais, Joinville, 2012.

OGEDA, T. L., PETRI, D.F.S., Hidrólise enzimática de biomassa. Química Nova, v.33(7), p.1549-1558, 2010.

PEREZ, B. B., VENTORIM, G., COMELATO, J. S. Otimização da extração alcalina com peróxido de hidrogênio em sequência de branqueamento com aplicação de baixo fator kappa. XXIII Congresso de iniciação científica, UNESP, 2011.

ROSSELL, C. E. V., ZAINAGHI, G. Produção de etanol combustível pela hidrólise enzimática. Cap. 9. In: Álcool Combustível. Instituto Euvaldo Lodi: Brasília, p. 123-138. p.163. 2008.

SEGAL, L.; CREELY, J.J.; MARTIN, A.E.; CONRAD, C.M. An empirical method for estimating the degree of crystallinity of native cellulose using the X-ray diffractometer. Textile Research Journal, v.29(10), p.786-794, 1959.

SILVA, D. J. Química da parte úmida em processo de fabricação de papel - Interações em interfaces sólido-líquido. 2010. 243 p. Tese de Doutorado.

SILVA, D.J.; D’ALMEIDA, M.L.O.; KOGA, M.T. Isolamento de nanocristais a partir de pasta celulósica kraft branqueada de eucalipto. In:44 Congresso e exposição internacional de celulose e papel, São Paulo, 2011.

SILVEIRA, L.; WISBECK, E., Caracterização e utilização do resíduo de algodão da indústria têxtil para a produção de corpos frutíferos de Pleurotus ostreatus DSM 1833. In: VI Congresso Brasileiro de Algodão. 13 a 16 agosto 2007 Uberlândia MG.

SOARES, M. L. Efeitos do teor de lignina na sacarificação e fermentação simultânea do bagaço de cana-de-açúcar para produção de etanol. 2012. 54 p. Dissertação de Mestrado.

TAHERZADEH, M. J., KARIMI, K., Acid-based hydrolysis processes for ethanol from lignocellulosic materials: a review. BioResources, v. 2 (3), p. 472-499, 2007.

TAPPI - Technical Association for Pulp and Paper Industries. Test methods. Atlanta, 2002/2003.

WENZL, H.F.J. The Acid Hydrolysis of Wood. Cap. IV In: The Chemical Technology of Wood. Ed. Academic Press, New York, p.157-252.p.692, 1970. 